\title{
THE EFFECT OF GENTAMICIN ON CALCIUM UPTAKE BY RENAL MITOCHONDRIA
}

\author{
Malinee Sastrasinh, Joel M. Weinberg ${ }^{1}$, and H. David Humes ${ }^{2}$
}

Departments of Internal Medicine, Veterans Administration Medical Center and University of Michigan, Ann Arbor, Michigan 48105

(Recelved In final form April 16, 1982)

\section{Summary}

The effect of the nephrotoxic aminoglycoside antibiotic, gentamicin, on calcium uptake by renal cortical mitochondria was assessed in vitro. Gentamicin was found to be a competitive inhibitor of mitochondrial $\mathrm{Ca}^{++}$uptake. This effect displayed a dose response with a $\mathrm{K}_{j}$ of $233 \mu \mathrm{M}$ and occurred at gentamicin concentrations below those that inhibit mitochondrial electron transport. These results further demonstrate the potential for gentamicin to alter membrane function and thereby contribute to toxic cell injury via its interactions with divalent cations.

Gentamicin is a polycationic, aminoglycoside antibiotic used frequently for the treatment of serious gram-negative infections. Nephrotoxicity is a side effect of this agent, and gentamicin nephrotoxicity is a frequent cause of acute renal failure in the clinical setting (1). The biochemical basis of renal cell injury in both nephrotoxic and ischemic acute renal failure appears to be the disruption of normal membrane function and integrity (2). Alterations in plasma and mitochondrial membrane structure and function are probably critical, and gentamicin provokes substantial derangements in both membrane systems early in developing nephrotoxicity (3).

The mechanisms for the direct in vitro effects of gentamicin at the inner mitochondrial membrane have been recently elucidated $(4,5)$. Due to its cationic structure, gentamicin apparently competes with $\mathrm{Mg}^{++}$at sites on the inner mitochondrial membrane where $\mathrm{Mg}^{7+}$ regulates the monovalent cation permeability of the membrane. Once occupying these sites, however, gentamicin does not limit $\mathrm{Na}^{+}$and $\mathrm{K}^{+}$permeability to the same degree as $\mathrm{Mg}^{++}$. Mitochondrial swelling, accelerated State 4 and inhibited State 3 and DNP-uncoupled rates result. Since $\mathrm{Mg}^{++}$is also an important regulator of mitochondrial $\mathrm{Ca}^{++}$uptake (6), we undertook the present series of experiments assessing the effect of gentamicin on mitochondrial $\mathrm{Ca}^{++}$uptake to further delineate the manner in which gentamicin interacts with this important intracellular membrane system.

\section{Methods}

Renal cortical mitochondria were isolated as previously detailed (7). Mitochondrial oxygen consumption was measured polarographically at $30{ }^{\circ} \mathrm{C}$ in a closed $1.4 \mathrm{ml}$ vessel with stirring bar and thermostatically controlled bath (Model K-1C, Gilson Medical Electronics, Inc., Middleton, Wisc.). The standard incubation medium contained $75 \mathrm{mM} \mathrm{KCl}, 100 \mathrm{mM}$ sucrose, $10 \mathrm{mM}$ Tris-

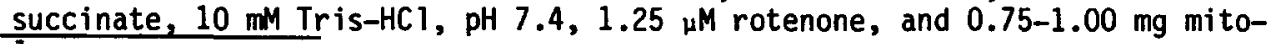
$l$ Dr. Weinberg is a Research Associate of the Veterans Administration.

2 To whom reprint requests should be sent. 
chondrial protein. For various experiments, concentrated stock solutions of gentamicin, $\mathrm{MgCl}_{2}$, or the ionophore, $\mathrm{A} 23187$, were added to the incubation medium to attain desired concentrations.

The initial rate of mitochondrial calcium uptake as a function of the incubation medium free calcium concentration was determined according to the method of Reed and Bygrave ( 8 ). $0.1 \mathrm{ml}$ of the concentrated mitochondrial suspension $(6-8 \mathrm{mg} / \mathrm{ml})$ was added to $0.4 \mathrm{ml}$ of incubation medium so that the final solution contained $120 \mathrm{mM} \mathrm{KCl}, 25 \mathrm{mM}$ sucrose, $10 \mathrm{mM}$ Tris-succinate, and $10 \mathrm{mM}$ Tris- $\mathrm{HCl}, \mathrm{pH} 7.4$. Incubations were carried out at $24^{\circ} \mathrm{C}$. After 2 minutes preincubation, mitochondrial $\mathrm{Ca}^{++}$uptake was initiated by the addition of $0.5 \mathrm{ml}$ of an identical solution also containing $1 \mu \mathrm{Ci}{ }^{45} \mathrm{Ca}^{++}, 10 \mathrm{mM}$ nitrilotriacetic acid (NTA), and varying concentrations of $\mathrm{CaCl}_{2}$ to attain various free $\mathrm{Ca}^{++}$concentrations in the medium. The free $\mathrm{Ca}^{++}$activity of this final incubation solution was measured directly as detailed below. The uptake of $\mathrm{Ca}^{++}$was terminated after 10 seconds with the addition of $1 \mathrm{ml}$ of ice-cold quench solution containing $120 \mathrm{mM} \mathrm{KCl}, 10 \mathrm{mM}$ Tris-succinate, $5 \mathrm{mM}$ NTA, $6 \mu$ M ruthenium red, $10 \mathrm{mM}$ Tris-ethylene glycol bis-( $\beta$-aminoethylether $) \mathrm{N}$, $\mathrm{N}^{\prime}$-tetraacetic acid (EGTA), pH 7.4. $0.5 \mathrm{ml}$ of the quenched mitochondrial solution was added to $3 \mathrm{ml}$ of ice-cold rinse solution, containing $120 \mathrm{mM} \mathrm{KCl}$, $10 \mathrm{mM}$ Tris- $\mathrm{HCl}, \mathrm{pH} \mathrm{7.4}$, and filtered through $0.5 \mu \mathrm{m} \mathrm{Millipore} \mathrm{cellulose}$ acetate filters (EHWP). The mitochondria collected on the filter were washed with an additional $6 \mathrm{ml}$ of rinse solution. The filters were placed in scintillation vials containing Aquasol (New England Nuclear) and counted in a scintillation counter. Mitochondrial protein was determined by the method of Lowry et al. (9). The initial rates of mitochondrial calcium uptake are expressed as nmol $\mathrm{Ca}^{++} / \mathrm{mg}$ mitochondrial protein/10 $\mathrm{sec}$.

Free $\mathrm{Ca}^{++}$activity in the final incubation solution containing $120 \mathrm{mM}$ $\mathrm{KCl}, 5 \mathrm{mM}$ NTA, $10 \mathrm{mM}$ Tris-HC $7, \mathrm{pH} 7.4$ was measured directly by a $\mathrm{Ca}^{++}$ selective electrode (Radiometer type F2112Ca) as described by Nichols (10). The electrode was calibrated by buffers containing $75 \mathrm{mM} \mathrm{KCl}, 5 \mathrm{mM}$ potassium NTA, $50 \mathrm{mM} 2-\{[2-$ hydroxy-1,1-bis(hydroxymethy 1)-ethyl] amino\}ethanesulphonic acid (TES) (potassium salt), $\mathrm{pH} 7.0$, and various calcjum concentrations. For calibration, the apparent stability constant, $8.69 \times 10^{3}$, was used for NTA at pH $7.0(10)$.

${ }^{45} \mathrm{CaCl}_{2}$ was obtained from New England Nuclear Corp.; A23187 was a gift from Dr. Robert Hamill of Eli Lilly Co. All other reagents were obtained from Sigma Chemical Co. A23187 was dissolved in absolute ethanol and gentamicin was prepared as aqueous Tris-gentamicin- $\mathrm{SO}_{4}, \mathrm{pH} 7.4$, in concentrations to deliver the required quantity in $10 \mu l$ aliquots. Ruthenium red was used without further purification.

\section{Results}

Effect of gentamicin on the A23187-induced $r$ ise in mitochondrial respiration

In isolated mitochondria, the divalent cation ionophore, A23187, produces stimulation of mitochondrial respiration due to persistent, energy-dissipating cycling of calcium across the inner mitochondrial membrane (6). The mitochondrial respiratory response to A23187 has, therefore, been used as a sensitive, dynamic index of mitochondrial $\mathrm{Ca}^{++}$uptake. In this regard, as seen in Fig. 1, $2 \mu M$ A23187 produced an increase in mitochondrial oxygen consumption from a basal rate of $108 \pm 3$ to $186 \pm 8$, or an average increase of $78 \pm 8$ nanoatom equivalents oxygen/min/mg protein $(p<.001)$. This A23187-mediated increment in mitochondrial respiration, however, was progressively and significantly diminished by 0.1 and $0.5 \mathrm{mM}$ gentamicin. Furthermore, the inhibitory effect of gentamicin on the respiratory response to A23187 was additive to the inhibition produced by $0.5 \mathrm{mM} \mathrm{Mg}{ }^{++}$. 

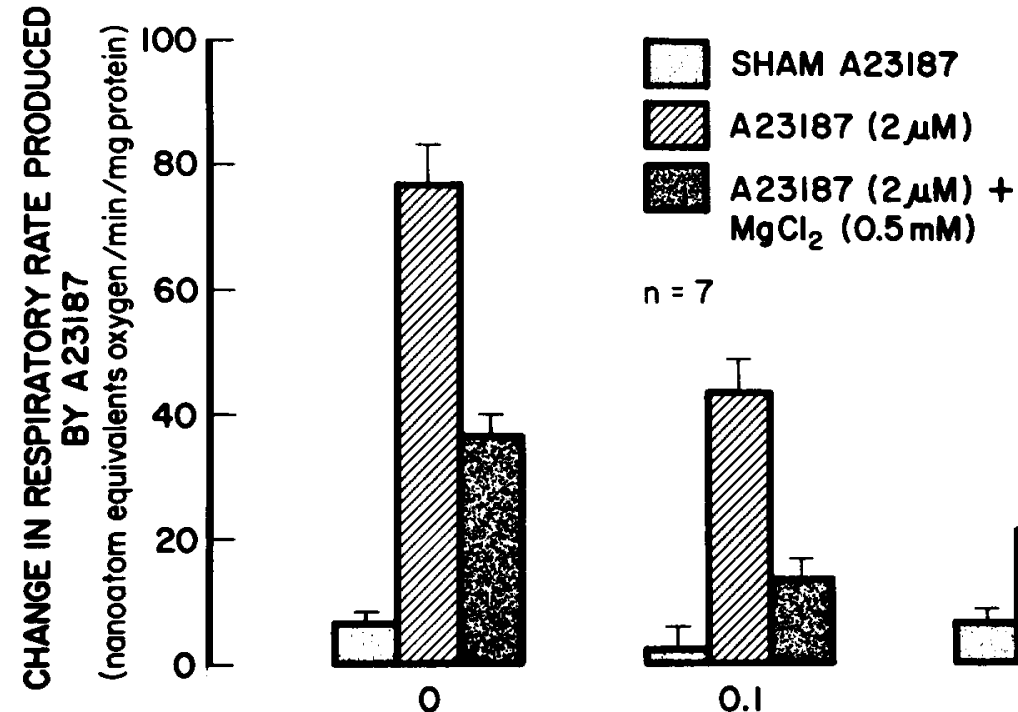

$n=7$

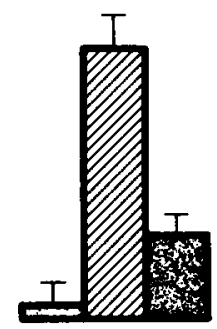

0.1

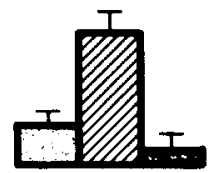

0.5

\section{GENTAMICIN (mM)}

FIG. 1

Effects of gentamicin alone and gentamicin $+\mathrm{MgCl}_{2}$ on the change in mitochondrial respiration induced by the calcium ionophore, A23187. Each experiment was started by adding mitochondria to the respiratory medium detailed under Methods, containing the desired level of $\mathrm{Mg}^{++}$and/or gentamicin. Mitochondrial $\mathrm{Ca}^{++}$levels averaged $30-40 \mathrm{nmol} / \mathrm{mg}$ protein. After 2 minutes, either A23187 or sham solution $(10 \mu 1$ ethanol) were added and the resulting initial rate of respiration was measured.

\section{Effect of gentamicin on initial rate of mitochondrial calcium transport}

Since the respiration experiments only assessed this mitochondrial transport process indirectly, direct measurements were carried out to assess the effect of gentamicin on initial velocities of mitochondrial $\mathrm{Ca}^{++}$uptake using $45 \mathrm{Ca}^{++}$and an EGTA-ruthenium red quench technique (8). The initial rate of mitochondrial calcium uptake as a function of medium $\mathrm{Ca}^{++}$concentrations is shown in Figs. 2 and 3 . As shown in $\mathrm{Fig.} \mathrm{2,} \mathrm{at} \mathrm{low} \mathrm{Ca}^{++}$concentrations, the relationship is sigmoid rather than hyperbolic. By graphical analysis, the $K_{m}$ and $V_{\max }$ were determined to be $12.0 \mu \mathrm{M}$ and $30 \mathrm{nmole} / \mathrm{mg}$ protein/10 sec, respectively (Fig. 3). As shown in Figs. 2 and 3 , gentamicin had no effect on $V_{\max }$ but increased the $\mathrm{K}_{\mathrm{m}}$ of the $\mathrm{Ca}^{++}$uptake process from the control value of 12.0 to 13.3 , and $60.0 \mu \mathrm{M}$ for gentamicin concentrations of .25 and $.50 \mathrm{mM}$, respectively. Analysis by Dixon plot (Fig. 4) confirmed that gentamicin is a competitive inhibitor of mitochondrial $\mathrm{Ca}^{++}$ uptake with an approximate $\mathrm{K}_{i}$ of $233 \mu \mathrm{M}$. $\mathrm{Mg}^{++}$also substantially inhibited mitochondrial $\mathrm{Ca}^{++}$uptake in this system (data not shown) similar to the effect observed in the ionophore experiments. However since $\mathrm{Mg}^{++}$ competes with $\mathrm{Ca}^{++}$for NTA binding and thereby alters free $\mathrm{Ca}^{++}$activity, this interaction was not quantitated using the Ca/NTA buffer system. 


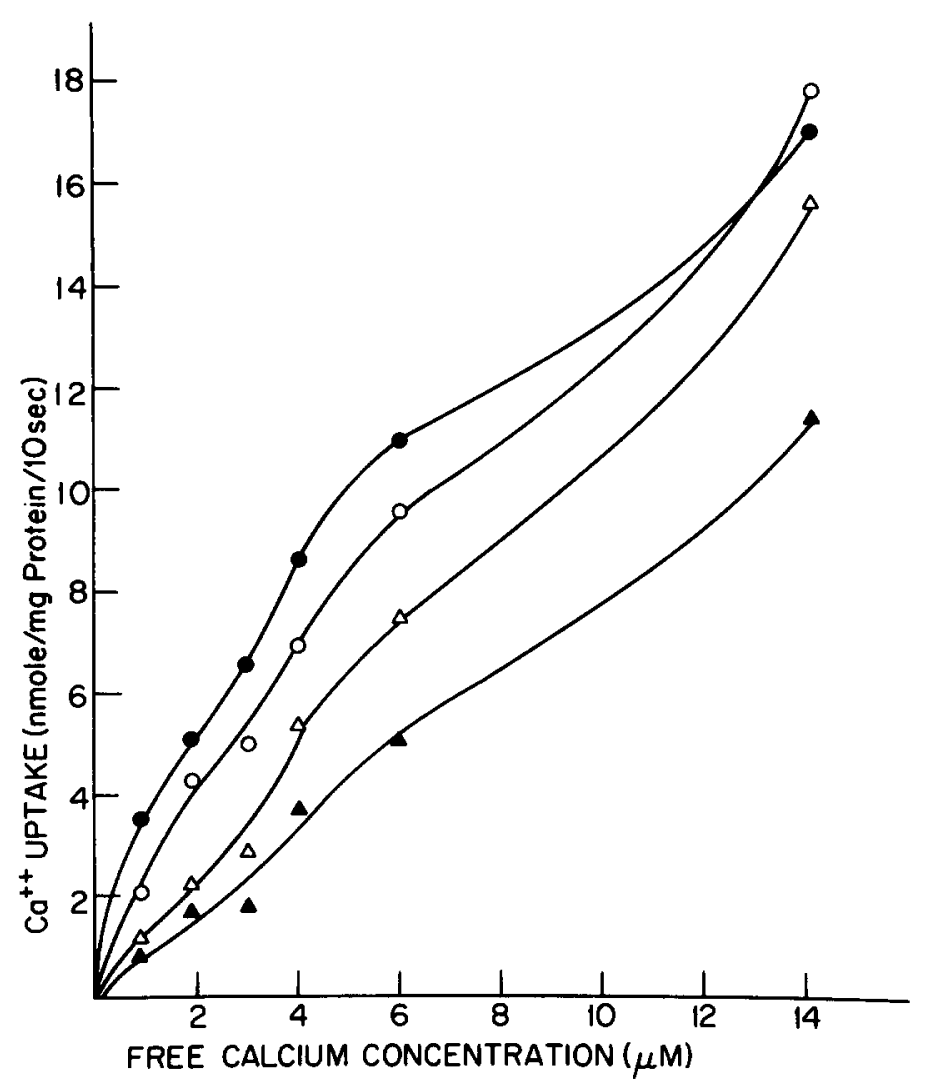

FIG. 2

Effect of various gentamicin concentrations ( $\bullet$, control; $0,0.025 \mathrm{mM}$; $\Delta, 0.25 \mathrm{mM} ; \Delta, 0.50 \mathrm{mM}$ ) on mitochondrial $\mathrm{Ca}^{++}$uptake at low free calcium concentrations.

\section{Discussion}

These data demonstrate that the aminoglycoside antibiotic, gentamicin, is a competitive inhibitor of mitochondrial $\mathrm{Ca}^{+7}$ uptake. This conciusion is based upon both indirect and direct measurements. An indirect assessment of mitochondrial $\mathrm{Ca}^{++}$uptake was made by measuring the rate of mitochondrial respiration after the addition of the divalent cation ionophore A23187. The addition of A23187 to an isolated mitochondrial preparation induces release of endogenous mitochondrial $\mathrm{Ca}^{++}$and energy-dissipating reuptake of $\mathrm{Ca}^{++}$via the electrophoretic $\mathrm{Ca}^{++}$uniport system $(6)$. The resulting steady state recycling of $\mathrm{Ca}^{++}$across the mitochondrial inner membrane uncouples oxidative phosphorylation and increases mitochondrial oxygen consumption. The magnitude of the rise in respiration correlates with the rate of $\mathrm{Ca}^{++}$uptake and is, therefore, sensitive to changes in the mitochondrial $\mathrm{Ca}^{++}$uptake 


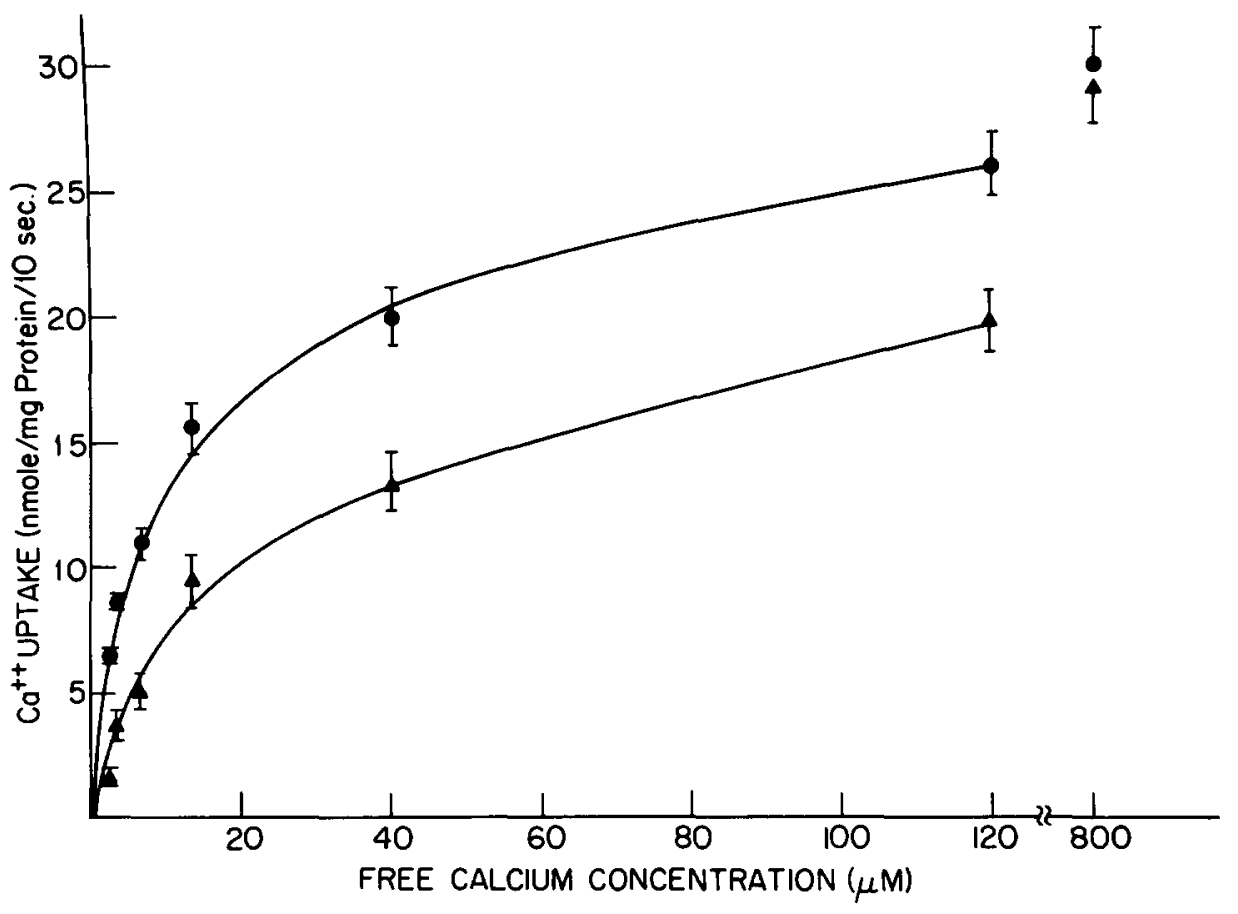

FIG. 3

Mitochondrial $\mathrm{Ca}^{++}$uptake at various medium free $\mathrm{Ca}^{++}$concentrations in the presence $(\Lambda)$ and absence $(\bullet)$ of $0.5 \mathrm{mM}$ gentamicin.

process. In this regard, the data presented here demonstrated that gentamicin significantly decreased the A23187-mediated increase in mitochondrial respiration, thereby suggesting that gentamicin inhibited mitochondrial $\mathrm{Ca}^{++}$uptake. This gentamicin effect was dose dependent, since $0.5 \mathrm{mM}$ was more effective than $0.1 \mathrm{mM}$, and was additive to a submaximal concentration of $\mathrm{Mg}^{++}$, a well established competitive inhibitor of mitochondrial $\mathrm{Ca}^{++}$uptake (6).

Direct measurement of $\mathrm{Ca}^{++}$uptake also demonstrated that gentamicin inhibited mitochondrial $\mathrm{Ca}^{++}$uptake. Initial velocities of mitochondrial $\mathrm{Ca}^{++}$uptake were assessed with $45 \mathrm{Ca}^{++}$in a nitrilotriacetic acid (NTA) buffer system and with an EGTA-ruthenium red quench technique described by Reed and Bygrave (8). NTA is a $\mathrm{Ca}^{++}$chelator which effectively buffers $\mathrm{Ca}^{++}$in the important physiologic region of $10^{-6}-10^{-4} \mathrm{M}$ free $\mathrm{Ca}^{++}$. The use of an NTA/Ca ${ }^{++}$buffer system generates stable free $\mathrm{Ca}^{++}$ concentrations, so that substantial mitochondrial uptake of $\mathrm{Ca}^{++}$will not perturb the initial free $\mathrm{Ca}^{++}$concentration even at low free $\mathrm{Ca}^{++}$ concentrations. The quenching of $\mathrm{Ca}^{++}$transport with a mixture of the high-affinity, non-competitive inhibitior of mitochondrial $\mathrm{Ca}^{++}$transport, ruthenium red, and the high-affinity $\mathrm{Ca}^{++}$chelator, EGTA, allows the measurement of short, well-defined reaction times while simultaneously removing externally bound $\mathrm{Ca}^{++}$. In this experimental system, gentamicin increased the $\mathrm{K}_{m}$ for the $\mathrm{Ca}^{++}$transport process in a dose-dependent manner without affecting the $V_{\max }$. The $K_{i}$ of this competitive inhibition of gentamicin on $\mathrm{Ca}^{++}$uptake was calculated to be $233 \mu \mathrm{M}$ by Dixon plot. 


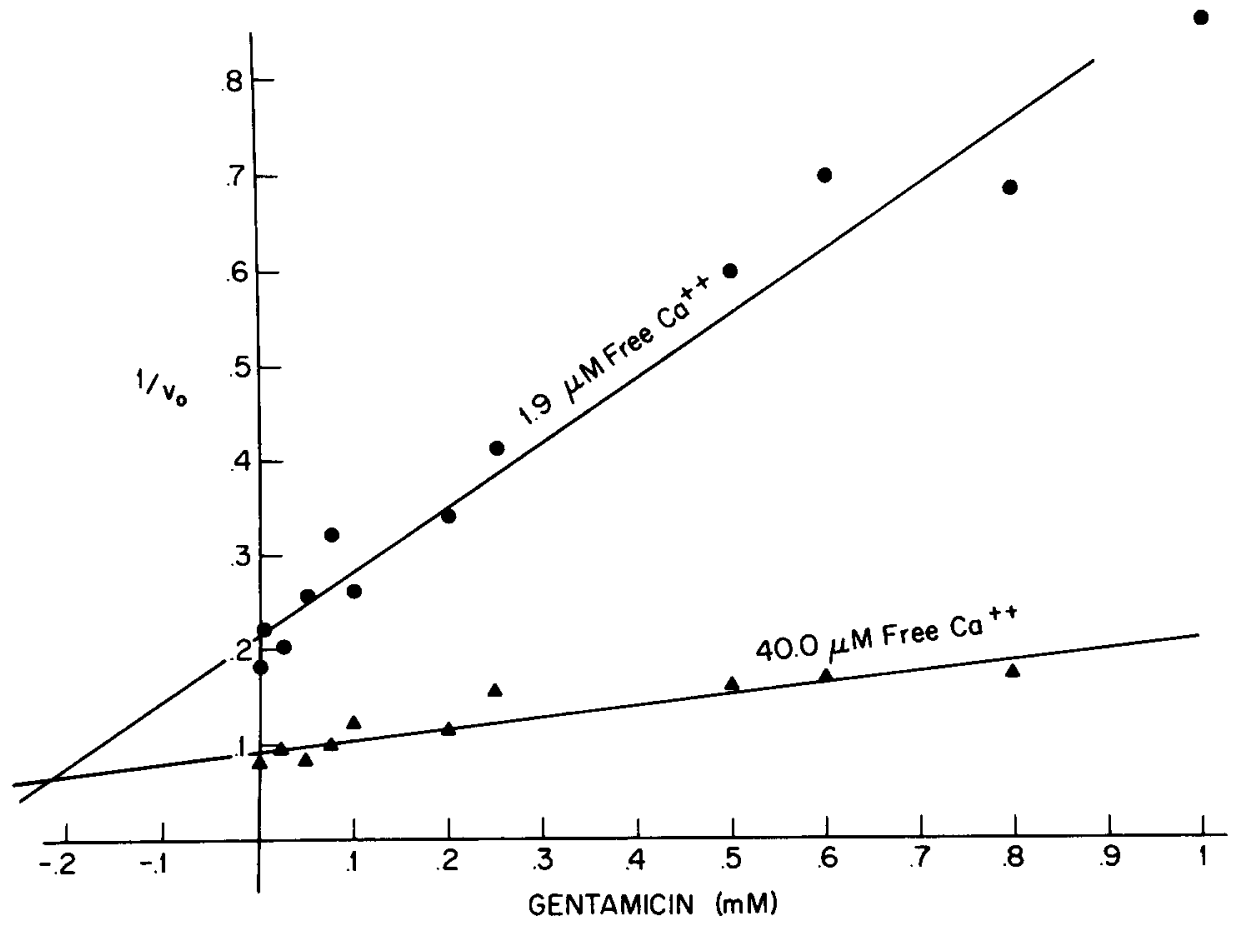

FIG. 4

Dixon plot for the inhibition of mitochondrial $\mathrm{Ca}^{++}$uptake by gentamicin. $v_{0}$ is the initial rate of mitochondrial $\mathrm{Ca}^{++}$uptake.

The data also demonstrated that at low free $\mathrm{Ca}^{++}$concentrations, the relationship between the medium $\mathrm{Ca}^{++}$concentration and initial velocity of the mitochondrial transport process is sigmoid rather than hyperbolic. This sigmoidicity has been well described previously in both liver (11) and kidney (12) mitochondria and has been interpreted to reflect a positive cooperativity between $\mathrm{Ca}^{++}$binding sites on the transporter. Since Hill coefficients have been reported to be between 1.6-1.7, a minimum of two interacting binding sites have been postulated. From our experiments the $K_{m}$ and $V_{\max }$ of mitochondrial $\mathrm{Ca}^{++}$uptake were determined to be $12.0 \mathrm{\mu M}$ and $30 \mathrm{nmole} / \mathrm{mg}$ protein $/ 10 \mathrm{sec}$ respectively, values slightly lower than those reported by Studer and Borle for renal mitochondria (12) and higher than those reported by Reed and Bygrave for liver mitochondria (11).

The manner in which mitochondria handle $\mathrm{Ca}^{++}$is a complex process dependent both on uptake and efflux pathways (13). The uptake transport occurs via an electrophoretic uniport system driven by the electrical gradient generated across the mitochondrial inner membrane by proton extrusion (14). Specific inhibitors of this uptake process have been described and include ruthenium red, lanthanum, and magnesium $(6,15)$. These compounds are cationic and are capable of binding to negative charges along the membrane. This charge interaction appears to be the basis of their inhibitory action on mitochondrial $\mathrm{Ca}^{++}$transport. The binding of $\mathrm{Ca}^{++}$to $\mathrm{its}$ carrier is an obligatory initial step in its transport and is due to a charge interaction 
between $\mathrm{Ca}^{++}$and an anionic site (11). Interaction with this binding site by other cationic substances would effectively inhibit $\mathrm{Ca}^{++}$uptake. Since gentamicin is a polycation, the mechanism of gentamicin's inhibitory effect on mitochondrial $\mathrm{Ca}^{++}$uptake is most likely due to a similar interaction.

Mitochondrial $\mathrm{Ca}^{++}$uptake is primarily electron transport limited (6). Gentamicin, however, inhibited mitochondrial $\mathrm{Ca}^{++}$uptake at concentrations lower than those required to decrease electron transport. In test conditions similar to those employed in these $\mathrm{Ca}^{++}$transport studies, i.e., in the absence of EDTA, gentamicin inhibits State 3 and DNP-uncoupled respiration only at concentrations greater than $1 \mathrm{mM}(4)$. In contrast, gentamicin concentrations as low as $.025 \mathrm{mM}$ inhibited mitochondrial $\mathrm{Ca}^{++}$uptake. The inhibitory effect of gentamicin on this transport process, therefore, appears to be independent of its effect on mitochondrial electron transport. The present paper adds to a growing body of data demonstrating the potential for gentamicin to interact with divalent cations on subcellular membranes of the renal tubular epithelial cell and thereby influence important functional properties whose derangement may contribute to its nephrotoxicity.

\section{References}

1. G.B. APPEL and H.C. NEU, N. Engl. J. Med. $296722-729$ (1977).

2. H.D. HUMES and J.M. WEINBERG, Min. Elect. Met. In press.

3. H.D. HUMES, J.M. WEINBERG and T.C. KNAUSS, Am. J. Kid. Dis. In press.

4. J.M. WEINBERG and H.D. HUMES, Arch. Biochem. Biophys. 205 222-231 (1980).

5. J.M. WEINBERG, P.G. HARDING and H.D. HUMES, Arch. Biochem. Biophys. 205 232-239 (1980).

6. S.M. HUTSON, D.R. PFEIFFER and H.A. LARDY, J. Biol. Chem. 251 5251-5258 (1976).

7. J.M. WEINBERG, P.G. HARDING and H.D. HUMES, J. Biol. Chem. 257 60-67 (1982).

8. K.C. REED and F.L. BYGRAVE, Anal. Biochem. 67 44-54 (1975).

9. O.H. LOWRY, N.J. ROSEBOUGH, A.L. FARR and J.R. RANDALL, J. Biol. Chem. 193 265-275 (1951).

10. D.G. NICHOLLS, Biochem J. 176 463-474 (1978).

11. K.C. REED and F.L. BYGRAVE, Eur. J. Biochem. 55 497-504, (1975).

12. R.K. STUDER and A.B. BORLE, Arch. Biochem. Biophys. 203 707-718 (1980).

13. D.G. NICHOLLS and M. CROMPTON, FEBS Letters 111 261- 268 (1980).

14. F.L. BYGRAVE, Curr. Topics Bioenerg. 6 259-318 (1977).

15. K.C. REED and F.L. BYGRAVE, Biochem. J. 140 143-155 (1974). 